\title{
A Fenomenologia como Método de Investigação nas Filosofias da Existência e na Psicologia
}

\author{
Ana Maria Lopez Calvo Feijoo ${ }^{1}$ \\ Universidade do Estado do Rio de Janeiro \\ Cristine Monteiro Mattar \\ Universidade Federal Fluminense
}

\begin{abstract}
RESUMO - Este artigo visa, primeiramente, explicitar como o método fenomenológico idealizado por Husserl encontra-se presente no pensamento de Heidegger, Sartre e Merleau-Ponty. Temas como consciência, intencionalidade e percepção, tratados por esses filósofos, serão apresentados, buscando destacar os três momentos, presentes em Husserl, imprescindíveis para uma investigação fenomenológica: a redução fenomenológica, a descrição dos vetores internos ao fenômeno e a explicitação da experiência. Em um segundo momento, indo ao encontro das considerações de Giorgi e Goto, pretende-se defender que a psicologia, ao apropriar-se do método fenomenológico em suas investigações, deve, considerando o contexto de sua área de estudo, manter-se fiel aos três momentos constitutivos do método fenomenológico.
\end{abstract}

Palavras-chave: fenomenologia, método, filosofias da existência, psicologia

\section{The Phenomenological Research Method in the Philosophies of Existence and in the Psychology}

\begin{abstract}
This article aims, first, to explain how the phenomenological method devised by Husserl is present in the thought of Heidegger, Sartre and Merleau-Ponty. Themes addressed by the philosophy as conscience, intencionality and perception will be discussed in order to show the three indispensable moments for a phenomenological research highlighted by Husserl: phenomenological reduction; description of internal vectors to the phenomenon and explanation of experiences. On the second, it going to meet the considerations of Giorgi and Goto, it argue that the Psychology the ownership of the phenomenological method in their investigations, should, considering the context of your study area, remain faithful at the three constituent moments of the phenomenological method.
\end{abstract}

Keywords: phenomenology, method, philosophies of existence, psychology

O presente estudo sobre fenomenologia e método pretende, primeiramente, explicitar como o método fenomenológico idealizado por Edmund Husserl (18591938) encontra-se presente nas filosofias da existência, mais especificamente, em Heidegger, Sartre e Merleau-Ponty ao desenvolverem seus estudos sobre as temáticas existenciais. E ainda, a partir da fenomenologia e da filosofia da existência, visa-se também mostrar como a psicologia, em uma tentativa de distanciar-se das referências científico-naturais, segue o caminho do método fenomenológico, tal como ocorreu com as filosofias da existência, como se pode notar no trabalho de dois autores contemporâneos, Giorgi (2006) e Goto (2008).

A escolha dos filósofos da existência, Heidegger, Sartre e Merleau-Ponty, ocorreu pelo fato de que os três apontam para a importância da máxima da fenomenologia de Husserl que consiste em ir às coisas mesmas quando se pretende investigar um fenômeno. Os três recebem essa definição pelo fato de manterem a pretensão de se afastarem dos critérios idealistas e realistas, estabelecendo, assim, um marco diferenciador entre as filosofias que se preocupam com a essência imutável

1 Endereço para correspondência: Instituto de Psicologia FenomenológicoExistencial do Rio de Janeiro, Rua Barão de Piracinunga, 62, Tijuca, Rio de Janeiro, RJ, Brasil, CEP. 20521-170.E-mail: ana.maria.feijoo@ gmail.com das coisas e as filosofias que pretendem retornar ao âmbito onde a existência mesma se dá.

Cabe ressaltar que, com o termo existencial, não se pretende referir, como é comum no âmbito da psicologia, ao efetivamente presente. Se assim fosse, recair-se-ia em uma hipostasia do espaço. Existencial, tal como tomado pelos filósofos que pensam o espaço de realização do existir, diz respeito às possibilidades mais originárias daquele que existe no seu encontro, também originário, com o mundo.

A eleição dos filósofos da existência Heidegger, Sartre e Merleau-Ponty deve-se ao fato de que os três, em suas diferentes perspectivas, encontraram na fenomenologia fundada por Husserl, um método que poderia conduzi-los à estrutura ou a dinâmica em que o fluxo da vida acontece em sua cotidianidade. Nesse sentido é que se irá buscar aqui o método fenomenológico em seus três momentos constitutivos: a redução fenomenológica, a descrição dos vetores internos ao fenômeno e a explicitação das experiências, como aparecem no pensamento filosófico de Martin Heidegger (1889-1976), Jean-Paul Sartre (1905-1980) e Maurice Merleau-Ponty (1908-1961), como eles mesmos testemunharam.

Assim, buscar-se-á em Heidegger a sua adesão à fenomenologia quando ele confessa em Meu caminho 
para a fenomenologia (1963/1991) como esse encontro aconteceu. Em Ser e tempo (1927/1989), na analítica do Da-sein, Heidegger já procede à investigação sobre o sentido do ser de modo fenomenológico. Sartre (1947/2005), por sua vez, assume a defesa do projeto da fenomenologia em Uma ideia fundamental da intencionalidade de Husserl e prossegue utilizando o método em muitos de seus escritos, como ocorre, por exemplo, em Esboço para uma teoria das emoções. Merleau-Ponty (1945/1994) inicia o prefácio de Fenomenologia da percepção com a questão $O$ que é fenomenologia? - e nessa mesma obra assume que segue os passos de Husserl para investigar a percepção. Este filósofo mostra uma íntima e estreita aproximação com a existência concreta quando, por exemplo, apresenta $A$ dúvida de Cézanne (Merleau-Ponty, 1945/2012) em uma perspectiva totalmente fenomenológica sobre a percepção e a expressão do artista. $\mathrm{O}$ mesmo pode-se afirmar a respeito das peças e romances sartrianos e dos seminários realizados por Heidegger na cidade de Zollikon ao longo de dez anos.

Para explicitar o modo como cada um dos filósofos existenciais, acima mencionados, articula o método fenomenológico à investigação de suas temáticas, é importante ressaltar que a fenomenologia nasce de uma inspiração de Husserl frente ao problema da busca do elemento universal presente nas filosofias modernas. Estas pressupunham que era possível conhecer a verdade essencial e, portanto, universal das coisas. E assim, na tentativa de alcançar a determinação das coisas, fazia-se necessária a presença daquele que pode alcançar essas determinações. A ideia que mantém, por um lado, aquele que é capaz de conhecer, alcançando as determinações do objeto, ou seja, o sujeito, e por outro lado o objeto, que tem suas determinações como coisa, opera uma cisão do sujeito que pergunta e da coisa investigada. A dúvida com relação à crença de que se pode alcançar a verdade universal por meio do sujeito que conhece ofereceu um momento propício para o surgimento da fenomenologia.

Com a fenomenologia, Husserl pretende superar as epistemologias realistas e idealistas, e é nessa superação que se encontra a gênese do projeto fenomenológico, também presente em Heidegger, Sartre e Merleau-Ponty. Essa tentativa se faz presente também nas chamadas perspectivas fenomenológico-existenciais em psicologia, quando pretendem investigar as temáticas existenciais ou as vivências, tais como consciência, tédio, medo, dentre outras, não como substâncias que sustentam as determinações em si mesmas, nem como determinações de uma interioridade psíquica, mas como atos que se constituem na cooriginariedade homem-mundo. E, é da perspectiva do ato que mostraremos como Heidegger, Sartre e Merleau-Ponty investigam o fenômeno da consciência - operando, na verdade, sua desconstrução - , mostrando fidelidade ao caminho proposto e seguido por Husserl na sua fenomenologia. Esse caminho pode ser acompanhado nos desdobramentos das investigações de Husserl (1901/2007) sobre a consciência, onde podemos apreender três momentos fundamentais: a redução fenomenológica, a descrição dos vetores internos ao fenômeno e a explicitação das experiências, como apresentados anteriormente.
Acrescenta-se, ainda, que é justamente o interesse pela investigação das vivências que aproxima as filosofias da existência da psicologia existencial. A primeira realiza sua tarefa pela reflexão filosófica, a segunda centra-se na materialidade da existência em sua realidade concreta. Logo, a consciência, a angústia, a liberdade, a percepção, o tédio, o medo, a cólera como atos interessam não só à filosofia como à psicologia.

O segundo objetivo desse estudo, como referido acima, diz respeito à defesa do modo como as pesquisas em psicologia devem tomar o método fenomenológico na investigação das suas temáticas. Há algum tempo, ocorre uma tentativa por parte dos pesquisadores da perspectiva fenomenológica em psicologia de articular o método idealizado pelo filósofo com as bases da psicologia fenomenológica. Neste estudo, serão apresentados os argumentos desenvolvidos por Amadeo Giorgi e Tommy Akira Goto, que tratam de viabilizar a articulação do método da filosofia com o da psicologia. No entanto, Giorgi (2006) ressalta que, para fazermos essa articulação, é necessário que o investigador oriundo da psicologia tenha domínio da fenomenologia de Husserl e que, em suas investigações, não prescinda de três momentos indispensáveis para que a pesquisa mantenha o referencial fenomenológico. São eles: adotar a atitude fenomenológica; encontrar o fenômeno que interessa estudar e usar o processo de variação livre da imaginação para determinar sua essência e, por fim, descrever cuidadosamente a essência da descoberta.

Goto (2008) aponta que a psicologia fenomenológica, nova disciplina proposta por Husserl em seus últimos escritos, pretende ser um fundamento metodológico sobre o qual se pode erguer uma psicologia cientificamente rigorosa. Essa psicologia foi concebida por Husserl como uma psicologia racional, pura, isto é, não experimental no estudo da subjetividade. Para Husserl, toda psicologia precisa partir da psicologia fenomenológica, a fim de garantir o rigor. Goto (2008) faz uma crítica aos autores que simplesmente transportam a fenomenologia para a psicologia, sem os devidos cuidados. Esse autor se refere à definição de Husserl de que a psicologia fenomenológica consiste numa nova disciplina paralela à fenomenologia filosófica, que não se distingue dela a princípio, e que seria o fundamento metódico sobre o qual se pode erguer uma psicologia empírica cientificamente rigorosa. Ou seja, Husserl (citado por Goto, 2008) postula que, para se fazer psicologia, é preciso partir de uma psicologia fenomenológica que seria uma descrição das estruturas psíquicas, descrição essa que é etapa indispensável para a constituição da própria fenomenologia. Afirma Goto (2008):

Se, com seu método, a fenomenologia favoreceu o encontro rigoroso com a subjetividade, de forma evidente e apodíctica, será também a partir dela que a psicologia poderá ter acesso direto à subjetividade enquanto tal e, assim, transcender a crise das ciências, retomando o sentido da existência como motivação originária. (p. 212).

A fim de atender aos objetivos deste trabalho, será apresentada inicialmente a fenomenologia husserliana, para em seguida serem trazidos os filósofos da existência em suas relações com o método fenomenológico. Por fim, será defendida a utilização do método fenomenológico como um 
caminho de investigação em psicologia, desde que seguidas as condições estabelecidas por Husserl.

\section{Fenomenologia e método em Husserl}

Dois elementos foram centrais no processo de gênese da fenomenologia: a concepção de método e a noção de intencionalidade. Husserl (1901/2007) inicia esclarecendo que é com a atitude fenomenológica, por meio da suspensão das hipostasias, que pretende alcançar aquilo que subjaz a determinação das coisas. Refere-se à hipostasia realista como um modo de pensar as estruturas como reais e que possuem determinações que podem ser alcançadas pelo método, e à hipostasia idealista como sendo atitude em que se acredita que a determinação das coisas se encontra na interioridade do sujeito que conhece.

Logo, Husserl utilizou-se do método fenomenológico para investigar o fenômeno da consciência. Para tanto, primeiramente, ele suspendeu de início todas as teorias acerca da consciência, fossem essas empíricas ou logicamente fundadas, suprimindo todas as perspectivas naturalizantes e assumindo uma postura antinatural frente ao fenômeno mesmo da consciência. Em um segundo momento, ao prescindir da ideia de uma substancialidade subjetiva subjacente aos atos, esse filósofo alcançou a essência do fenômeno pelo exercício do pensamento, acompanhando descritivamente a própria constituição da consciência em ato. Deste modo, encontrou a essência da intencionalidade como espaço de dação dos objetos, ou seja, os fenômenos.

Ao acompanhar o caminho descrito acima tal como percorrido por Husserl (1901/2007) na investigação da consciência, pode-se observar os seguintes momentos: 1redução fenomenológica em que o investigador suspende, de início, todas as teorias acerca da consciência, seja essa teoria empírica ou logicamente fundada. Ao suprimir as perspectivas naturalizantes, Husserl assume uma postura antinatural frente ao fenômeno; 2- descrição dos vetores internos ao fenômeno, na medida em que o investigador acompanha a própria constituição da consciência em ato e 3 - explicitação da experiência, alcançando, assim, a sua essência, ou seja, no caso da consciência, a intencionalidade. Logo, nas Investigações lógicas (1901/2007), Husserl, utilizando o método fenomenológico para investigar o fenômeno da consciência, alcança a essência desse fenômeno, a intencionalidade como espaço de dação dos objetos fenômeno, e concebe a consciência intencional como síntese incessante do fluxo temporal das experiências.

Assim, intencionalidade diz respeito ao incessante transcender de si mesmo, rompendo com o pressuposto de que é o sujeito que posiciona as coisas ou de que as coisas existem independentemente da consciência. Estruturas intencionais dizem sempre do caráter de cooriginariedade sujeito e objeto, ou seja, quando um dos pólos aparece o outro imediatamente acontece, sem nenhum intervalo espaço-temporal entre eles. Elimina-se, assim, a ideia de intervalo espaço-temporal e, consequentemente, de qualquer estrutura de causalidade. A consciência é, para este filósofo, transcendente, nunca se retém em si mesma, mas se vê projetada por seus próprios atos para o campo dos objetos correlatos. Na medida em que a consciência se realiza através de seus atos, ela sempre transcende o campo de realização desses atos.

Em síntese, duas considerações se fazem pertinentes com relação à filosofia de Husserl. Primeiro, que seu interesse incidia na investigação da consciência, porém, ele acreditava que o modo pelo qual esse fenômeno vinha sendo investigado, em meio às hipóstases, não alcançava a sua estrutura mais originária. Segundo, por não estar de acordo com os métodos realistas e idealistas de investigação da consciência, Husserl elabora outro caminho de acesso ao fenômeno que denominou fenomenológico, o qual consistia em acompanhar o fenômeno da consciência em seu campo de mostração para que, dessa forma, o mesmo aparecesse em sua essencialidade. Como se demonstrará a seguir, seu projeto influenciará de forma marcante as filosofias de Heidegger, Sartre e Merleau-Ponty.

\section{A investigação fenomenológica da estrutura da intencionalidade em Heidegger, Sartre e Merleau- Ponty}

Explicitar-se-á, agora, de que modo Heidegger, Sartre e Merleau-Ponty, que são referências constantes nos estudos sobre fenomenologia existencial, assumem a fenomenologia de Husserl como caminho para suas investigações. Os três, ao se posicionarem filosoficamente, vão ao encontro do pensamento de Husserl no que diz respeito à suspenção das hipostasias realistas e idealistas. E será fenomenologicamente, que Heidegger, Sartre e Merleau-Ponty irão proceder na investigação dos fenômenos da existência, ou seja, aqueles que acontecem no espaço de realização da existência.

Heidegger, por meio do método fenomenológico, radicaliza a noção de intencionalidade, abandonando qualquer referência à consciência, passando, então, investigar o Dasein (ser-aí). Sartre atém-se a estruturas que foram anteriormente temas da psicologia tais como a consciência, a emoção e a imaginação, porém, tomados como objetos a serem pesquisados de modo a poder descobrir as leis que regiam seus movimentos. Sartre, então, aponta para a necessidade de se ater às estruturas intencionais desses fenômenos. Merleau-Ponty, também crítico do modo como a psicologia experimental estudava as variáveis psicológicas, vai buscar na fenomenologia, especialmente na noção de intencionalidade tal como postulada por Husserl, elementos para uma revisão das noções de consciência na psicologia. Assim, Merleau-Ponty aponta em seus estudos para outro modo de proceder na investigação do fenômeno das expressões do homem.

Primeiramente, será mostrado como esses filósofos compartilharam com Husserl da crítica às filosofias realistas e idealistas. Depois, para ilustrar como esses três filósofos se mantêm nos três momentos imprescindíveis na investigação fenomenológica, tal como encontrados em Husserl: a redução fenomenológica, a descrição dos vetores internos ao fenômeno e a explicitação das experiências será apresentado como Heidegger, Sartre e Merleau-Ponty caminharam em suas investigações. 


\section{O caminho de Heidegger para a fenomenologia e o desvelamento do Dasein.}

Heidegger escreveu em 1963 Meu caminho para a fenomenologia para ser publicado em uma tiragem privada em homenagem a Hermann Niemeyer ${ }^{1}$. Nesse escrito, Heidegger (1963/1991) confessa que chegou a Husserl por meio das Investigações Lógicas, as quais ele diz que precisou ler por aproximadamente dez vezes para começar a entendê-las. Durante a leitura, se perguntava: "Em que consiste o elemento individualizador da Fenomenologia, já que não é nem a Lógica nem a Psicologia? Manifesta-se aqui uma disciplina filosófica inteiramente nova e que possui dignidade e nível próprios?" (1991, p.496). Na tentativa de responder às questões que ele mesmo formulara, Heidegger se entrega a leitura das Investigações e da obra Ideias para uma fenomenologia pura. No entanto, as dúvidas só começam a se esclarecer quando o filósofo da Floresta Negra assiste às aulas de Husserl. Diz Heidegger (1963/1991): "A atividade docente de Husserl consistia no progressivo exercício e na aprendizagem do ver fenomenológico; ele exigia tanto a renúncia a todo uso não crítico de conhecimentos filosóficos como impunha não trazer-se para o diálogo a autoridade dos grandes pensadores" (p. 497).

Heidegger começava a entender a fenomenologia, porém, quanto mais ouvia Husserl, mais se sentia próximo aos pensadores gregos, principalmente Aristóteles. Foram os estudos da Sexta Investigação, na qual Husserl distingue a intuição sensível da categorial, que levaram Heidegger a entender o porquê dela remeter-se a Aristóteles. Tratava-se de entender o "alcance para a determinação do significado múltiplo do ente" (Heidegger, 1963/1991, p.497). Heidegger conclui, então, que aquilo que para Husserl consistia em ato da consciência, para Aristóteles era Aletheia, desvelamento do que se apresenta: "Aquilo que as Investigações redescobriram como a atitude básica do pensamento revela-se como traço fundamental do pensamento grego, quando não da Filosofia como tal" (Heidegger, 1963/1991, p. 498).

O filósofo de Ser e tempo (1927/1989) vai analisar a questão do sentido do ser por meio do método fenomenológico. Para tanto, inicia com a investigação indo ao fenômeno da existência tal como ela se mostra no seu campo de mostração, ou seja, na medianidade cotidiana. Prescindindo de todas as filosofias da subjetividade, primeiramente, suspendeu as hipostasias realistas ou idealistas e acompanhando os vetores, ou seja, a dinâmica existencial em que a existência se dá em sua medianidade, alcançou a explicitação da experiência, a qual denominou Dasein, como a estrutura mais original da intencionalidade.

Importa realçar que, mesmo tendo como ponto de partida a fenomenologia de seu mestre Husserl, a quem dedica Ser e tempo (1927/1989), Heidegger, em sua analítica, com a concepção de Dasein rompe totalmente com a categoria da consciência tal qual a entendia a tradição filosófica. Em

1 Hermann Niemayer (1754-1828) nascido na Alemanha foi professor de teologia, escritor e poeta. Em 1807, foi deportado para Paris por Napoleão.
Seminários de Zollikon ${ }^{2}$ afirma o filósofo que difere de Husserl e de sua fenomenologia por não elaborar, com sua analítica, somente as estruturas de ser do Dasein, mas por colocar expressamente o ser-homem de modo geral como Dasein, diferentemente das determinações do homem como subjetividade e como consciência do eu transcendental (Heidegger, 2001). Diz, ainda, que a fenomenologia de Husserl permanece fenomenologia da consciência, impedindo a visão clara da hermenêutica fenomenológica do Dasein. A relação de Dasein e consciência necessitaria, segundo Heidegger, de uma discussão especial, pois ela é assinalada pela pergunta da relação fundamental entre ser-nomundo como Dasein e intencionalidade da consciência. De acordo com Heidegger (2001), pelo fato da consciência ter se tornado uma representação fundamental da filosofia moderna e a fenomenologia de Husserl também se manter nessa mesma linha de pensamento, a fenomenologia de Husserl ainda se encontra na tradição moderna, com o objetivo de descrever a consciência.

Heidegger, diferentemente de Husserl, considera em suas análises o mundo como horizonte histórico de sentidos e, ainda, que é o mundo que torna possível que algo se mostre como algo pela experiência fenomenológica.

\section{Sartre e sua ideia fundamental de intencionalidade.}

Sartre (1947/2005) apresenta em Uma ideia fundamental da intencionalidade de Husserl a sua imersão na fenomenologia de forma intensa. Ao tecer a crítica ao modo como o idealismo postula como se dá o conhecimento, Sartre cria a imagem da digestão em que o processo de assimilação produz uma transformação radical daquilo que se conhece. No idealismo, o ato de conhecer a coisa, faz com que essa se transforme, não permanecendo a mesma. Já ao referir-se ao modo de conhecer do realismo, Sartre (1947/2005) utiliza-se da imagem da aranha que come com os olhos, encontrando nas teias da razão a objetividade, para então determinar aquilo que cai na teia. No interior do realismo, a coisa é interpretada como uma realidade em si mesma, prescindindo totalmente da consciência.

Tanto na perspectiva idealista quanto na realista abre-se um fosso entre o sujeito e o objeto. No idealismo prevalece a ideia do substrato subjetivo e do sujeito egóico. E é esse sujeito que posiciona o mundo. No realismo, o sujeito permanece totalmente isento diante das coisas, cabendo-lhe apenas descrevê-las. A consciência é uma espécie de cera em que a realidade, por meio da experiência, vai produzindo marcas que se estruturam como conhecimento (Sartre, 1947/2005).

Diferentemente, do modo de se posicionar do idealismo e do realismo, Sartre (1947/2005) defende que, em uma postura fenomenológica, nós apreendemos o que se mostra, sem transformá-lo e sem prescindir da visada, apenas acompanhando os vetores daquilo que se apresenta,

2 Seminários organizados anualmente por Medard Boss entre 1959 e 1969 na cidade suíça de Zollikon, ao longo dos quais Heidegger procurou exercitar o olhar fenomenológico junto a uma assistência de médicos e psicoterapeutas. 
acompanhando a mobilidade estrutural do fenômeno. Outra expressão marcante, neste mesmo manuscrito, refere-se ao ver fenomenológico como um abrir de olhos.

A percepção fenomenologicamente pensada abre espaço para que a coisa percebida apareça como tal no seu horizonte de mostração, suprimindo, assim, a ideia de realidade objetiva ou subjetiva. A percepção, dessa forma, não é concebida como objetiva ou empírica e também não é uma faculdade que se encontra em uma interioridade. A percepção é ato de perceber e assim acontece no interior das relações intencionais. Nesse caso, a ação de ver se dá cooriginariamente com o visto. $\mathrm{O}$ ato de ver é uma celebração do acontecimento do fenômeno.

É por meio da atitude fenomenológica que Sartre investiga a consciência como explosão: "Ser é explodir para dentro do mundo" (1947/2005, p.56). O filósofo utiliza a metáfora da explosão para descrever a unidade originária consciência-mundo que libera o horizonte de conhecimento. A consciência não é interna, não é fechada em si mesma, a consciência é imediatamente pura exterioridade.

Assim, sujeito e objeto não estão em relação, sujeito e objeto são, eles mesmos, a relação. A consciência é fluxo, dinâmica, explosão. A essência da consciência é intencionalidade, um fora que se coloca junto à coisa sem que a coisa possa ser assimilada.

Sartre em Esboço para uma teoria das emoções (1948) inicia por colocar em questão as teorias psicológicas que pressupõem o afeto como advindo de uma consciência reflexiva. E, assim, procede à redução fenomenológica, primeira etapa da investigação fenomenológica, suspendendo as hipostasias psicologizantes. Nestas o afeto consistiria em um sentimento, fato ou estado da consciência. Sartre, imerso nas posições husserlianas acerca da consciência, busca na sua aparição seu caráter irrefletido e não posicional. Considerando a intencionalidade husserliana, atenta para o fato de que o afeto é ato e, como tal, o sujeito afetado e o objeto que afeta são indissociáveis, cooriginários. $\mathrm{O}$ afeto consiste em certo modo de apreender o mundo.

Sartre refere-se a diferentes modos de afetos ou emoções. Em um segundo momento, considerando os vetores internos ao fenômeno e descrevendo-os, com relação à emoção de medo, por exemplo, diz ele que o homem que tem medo teme algo que se mostra como efetivamente temeroso, seja uma rua deserta, seja o escuro, por fim, alguma situação que aponta para algo que se mostra ameaçador a sua existência. Sartre exemplifica a expressão de um verdadeiro sentido do medo na ação de fuga frente a uma situação ameaçadora, quando o lutador de boxe fecha os olhos ao atacar o adversário. Diz ele: "é uma consciência que trata de negar, através de um comportamento mágico, um objeto do mundo exterior e que chegará até esconder-se e esconder o objeto." (1948, p.61).

Por fim, Sartre explicita a experiência da expressão do homem pelo modo como o mundo se apresenta a ele sem a necessidade de uma consciência reflexiva, pelo contrário, ocorre um fluxo contínuo de intencionalidade. Ou seja, o ato como tal, se dá no espaço em que homem e mundo estão em jogo.

\section{Merleau-Ponty e o reposicionamento das essências na existência.}

Merleau-Ponty, fiel a crítica de Husserl ao idealismo e ao realismo e na mesma direção de Heidegger e de Sartre, defende que a fenomenologia é uma luta constante contra o idealismo kantiano, que pressupõe uma subjetividade transcendental, a qual possui as leis fundamentais que tornam possível o conhecimento. Nessa perspectiva, o que conhecemos é um objeto que se mostra no campo da experiência, no entanto, este é posicionado pelas estruturas do sujeito.

Merleau-Ponty (1945/1994), no prefácio de Fenomenologia da percepção, apresenta a fenomenologia, iniciando o texto com a seguinte questão: "O que é fenomenologia?" (1994, p.1), e reponde: “A fenomenologia é o estudo das essências, e todos os problemas, segundo ela, resumem-se em definir essências, a essência da percepção, a essência da consciência, por exemplo." (1994, p.1). MerleauPonty, nessa obra, pretende chegar à essência da percepção, fenomenologicamente. Refere-se à fenomenologia como uma filosofia transcendental que, ao suspender as afirmações da atitude natural, “[...]repõe as essências na existência” (p.1). Em síntese, conclui que investigar fenomenologicamente consiste em: "uma descrição direta de nossa experiência tal como ela é, e sem nenhuma deferência à sua gênese psicológica e às explicações causais que o cientista, o historiador ou o sociólogo dela possam fornecer" (MerleauPonty, 1994, p.1-2). E é pela compreensão do homem e do mundo em sua facticidade que esse filósofo investigará o fenômeno da percepção. Mundo, aqui, compreendido como presença inalienável, conjunto das relações objetivas tal como articuladas pela consciência.

Merleau-Ponty (1990), após reduzir todas as teorias idealistas acerca da percepção e da consciência, parte para buscar os vetores internos ao fenômeno, que lhe possibilitam ver o fenômeno em outras perspectivas, e conclui: "É por meu corpo que compreendo o outro, assim como é por meu corpo que percebo 'coisas'. Assim 'compreendido', o sentido do gesto não está atrás dele, ele se confunde com a estrutura do mundo que o gesto desenha" (Merleau-Ponty (1945/1994, p.25).

A relação entre a percepção e a arte é abordada por este filósofo em sua obra $O$ olho e o espírito, composto por três ensaios e, especificamente, no ensaio intitulado $A$ dúvida de Cézanne em que Merleau-Ponty (1945/2012) acompanhando atentamente a trajetória do pintor afirma que a arte é "uma operação da expressão" (p. 119). Logo, nessa mesma obra, conclui Merleau-Ponty que não são as leis da geometria nem as leis da consciência que conduzem o gesto do pintor. $\mathrm{O}$ que faz a pintura é o motivo da expressão do artista em sua totalidade e plenitude

Merleau-Ponty (2012) explicita a experiência da expressão, concluindo que os sentidos dos gestos não têm determinações dadas a priori, tal como defendiam as perspectivas idealistas, seja na filosofia, seja na psicologia, pois somente podem ser compreendidos em ato. A arte de 
Cézanne, por exemplo, se dá em uma experiência perceptiva e não pelo reconhecimento das leis que governam o comportamento de pintar. Da mesma forma, ao compreender a arte do outro não o fazemos pelo conhecimento das leis e das formas em que a pintura se expressa. Assim, MerleauPonty dá relevo à experiência sensível que fora totalmente abandonada pelos idealistas, sem recair em um realismo, que mesmo mantendo a experiência, subtrai totalmente o sentido da experiência que é dado justamente no espaço de intencionalidade. No seu percurso filosófico, o filósofo constrói argumentos a favor da tese de que é a percepção a modalidade original da consciência: "Neste sentido toda consciência é consciência perceptiva, mesmo a consciência de nós mesmos" (Merleau-Ponty, 1990, p.42). Merleau-Ponty toma a percepção como um abrir espaço para que o percebido apareça como ele é.

Com o exposto acima, pode-se acompanhar de que modo Heidegger, Sartre e Merleau- Ponty tomaram a fenomenologia em suas investigações sobre a consciência e como os três fenomenólogos assumem o método de Husserl, preservando os momentos imprescindíveis para que aconteça uma investigação fenomenológica. Conclui-se que os três mantiveram-se fiéis as exigências metodológicas impostas pelo mestre da fenomenologia, uma vez que assumiram a atitude fenomenológica ao reduzir tanto o empírico quanto as leis do pensar ao fenomenológico. Por isso, tomaram os fenômenos que pretendiam investigar de forma totalmente distinta do modo empírico ou lógico, deixando que o fenômeno aparecesse no seu campo de mostração. E, após assumirem a aparição do fenômeno pela descrição dos vetores internos ao mesmo, deixaram que esses vetores internos ao fenômeno se mostrassem por si mesmos. Por fim, descreveram aquilo que constitui a essência da descoberta. Assim, Heidegger, em uma postura totalmente radical, reduz a intencionalidade ao Dasein como abertura, ou seja, horizonte de mostração das coisas. Sartre, por sua vez, defendeu que a estrutura das emoções não se encontra em uma interioridade, mas na articulação consciência e mundo - intencionalidade. MerleauPonty rearticula a intencionalidade de modo a alcançar a sua essência na experiência da percepção, referindo-se à consciência perceptiva.

Por fim, pensar na fenomenologia seja de Heidegger, Sartre ou Merleau-Ponty permite compreender do que se trata numa atitude fenomenológica de investigação, o que possibilita que se tenha em mente os pressupostos fenomenológicos presentes no projeto husserliano, tais como foram sistematizados anteriormente. No entanto, cabe ainda pensar em como apropriar-se do método fenomenológico para as investigações em psicologia.

\section{A Fenomenologia como método de investigação em Psicologia}

Sabe-se que, atualmente, as investigações em psicologia têm buscado inspiração no método fenomenológico. Muitos estudiosos do tema realizam uma apropriação da fenomenologia para a psicologia, assim como os filósofos apresentados anteriormente o fizeram para seus estudos filosóficos. Estudiosos da psicologia fenomenológica nos advertem sobre o risco que corremos quando fazemos tal transposição (Giorgi, 2006; Castro \& Gomes, 2011), sem considerar o elemento mesmo da psicologia e então confundilo com aquilo que é pertinente à filosofia. Acerca disso, defende Giorgi (2006, p. 354) "Consequentemente, algum senso da disciplina em questão tem de ser considerado e articulado aos procedimentos filosóficos". Castro e Gomes (2011) referem-se a três modelos de transposição do método fenomenológico da filosofia para a psicologia, são eles: psicologia empírico-fenomenológica, fenomenologia experimental e neurofenomenologia. Estes autores, no entanto, comentam que, por diferentes motivos, esses "três modelos vislumbrados de transposição da lógica transcendental husserliana para a prática empírico-científica não aparentam ter alcançado, ou mesmo almejado uma reforma epistêmica sólida" (2011, p. 237). Com essas advertências, pode-se concluir que, se não forem tomados os devidos cuidados, corre-se o risco de se afirmar que se faz pesquisa fenomenológica em psicologia sem que efetivamente o método fenomenológico possa ser aplicado.

Tendo em vista que a adoção rigorosa da fenomenologia por Heidegger, Sartre e Merleau-Ponty foi o que permitiu o delineamento da filosofia em outras bases, existenciais, operando a desconstrução da visão de psiquismo, atos mentais e consciência como objetos naturais a serem explorados, pode-se concluir que a fenomenologia deverá ser o caminho metodológico trilhado na investigação em psicologia, ao menos em uma psicologia que se propõe a evitar que o espírito fique subordinado à vida natural, como um simples derivado desta. Mantendo-se fiel às considerações rigorosas defendidas por Husserl, a psicologia poderá alcançar aquilo que Castro e Gomes (2011, p. 239) denominaram de "uma reforma epistêmica sólida". Para tanto, acredita-se que, inspirando-se nos passos apropriados pela filosofia na utilização do método, sem que, no entanto, pretenda chegar à fenomenologia transcendental, a psicologia deve ater-se, no mínimo, aos seguintes momentos: a redução fenomenológica, a descrição dos vetores internos ao fenômeno e a explicitação das experiências. À psicologia bastam as reduções fenomenológica e psicológica, com a suspensão da crença em um mundo em si e em uma subjetividade em si, a fim de acessar os fenômenos psicológicos em seu mostrar-se originário.

Se os dois primeiros passos se conjugam com aqueles que Giorgi (2006) considerou imprescindíveis na filosofia-a atitude fenomenológica e a variação imaginativa - o terceiro parece se afinar mais com o contexto próprio a psicologia, pois que diz respeito às descrições das experiências dos indivíduos singulares, tais como apreendidas pelo investigador. Nesse aspecto, com o retorno da fenomenologia ao solo originário a partir do qual é possível toda episteme, inclusive da própria psicologia, esta, ao aliar-se ao método fenomenológico, poderá reformular seu modo de acesso ao fenômeno que a interessa mais de perto, a existência concreta, indo ao encontro da proposta de uma reforma epistêmica radical. (Castro \& Gomes, 2011).

Psicólogo estudioso da obra de Husserl no Brasil, Goto (2008) afirma que o matemático e filosofo alemão passou a elaborar uma psicologia fenomenológica dentro da fenomenologia filosófica, possibilitando a formação de 
uma nova abordagem na ciência psicológica. A psicologia fenomenológica não constitui apenas uma abordagem fenomenológica enquanto compreensão e visão de mundo, mas sim fundamento para a psicologia científica. Toda psicologia deve ser precedida de uma psicologia fenomenológica, no sentido de um esforço reflexivo pelo qual, no contato com a nossa própria experiência, elaboramos as noções fundamentais de que a psicologia se serve a cada momento. Os últimos escritos de Husserl mostram o caminho para a subjetividade transcendental, partindo do mundo da vida e da psicologia. A vida humana é vista como estrutura espiritual que é suporte constituinte do sentido do mundo.

$\mathrm{Na}$ volta às coisas primeiras retorna-se à própria subjetividade, o que pode ser feito através de três vias possíveis: cartesiana, psicológica e transcendental. Enquanto a evidenciação da subjetividade transcendental como estrutura primeira e fundamental de toda existência se opõe ao objetivismo da ciência, a via psicológica se lhe constitui como um caminho necessário de passagem para a fenomenologia transcendental, sendo essa via, para os psicólogos, o ponto de partida para uma investigação dos fenômenos existenciais com base na fenomenologia.

Ainda de acordo com Goto (2008), a psicologia fenomenológica de Husserl tem o intuito de "expor a expressividade psíquica" (p.211) da subjetividade transcendental, sendo, portanto, o "fundamento metódico sobre o qual se pode, por princípio, erguer-se uma psicologia empírica cientificamente rigorosa." (p. 211). Isto significa que o interesse do psicólogo fenomenólogo volta-se para as expressões existenciais que têm como condição de possibilidade o solo originário comum a todos os homens, exposto nas evidências pré-lógicas e pré-científicas, que Husserl chamou de subjetividade transcendental.

\section{Considerações Finais}

O artigo buscou explicitar, inicialmente, a importância do método fenomenológico concebido por Edmund Husserl como condição de possibilidade para investigações filosófico-existenciais, como foram as de Heidegger, Sartre e Merleau-Ponty. Em seguida, apontou para a viabilidade da metodologia fenomenológica nas investigações em psicologia. Destacou que uma psicologia que se pretenda fenomenológica deverá buscar, até as últimas consequências, as condições necessárias para legitimar esse caminho de investigação dos fenômenos psicológicos. Tentou-se, assim, responder às dúvidas que insistentemente se repetem: é possível articular filosofia e psicologia? Em outras palavras, é possível que um método próprio de investigação em filosofia possa ser abarcado pela psicologia? Para seguir envolvendose com essas questões, é preciso dar continuidade ao estudo da fenomenologia de Husserl e aos estudos dos psicólogos com base fenomenológica que também se inquietam com essas provocações. Além disso, faz-se necessário investigar, no âmbito da psicologia fenomenológica, as conclusões de pesquisas que conferem legitimidade à utilização do método fenomenológico em psicologia, sem deixar de ficar atento àquelas que apontam para as contradições e inadequações no uso desse método. Por esse caminho, poder-se-á buscar as bases sólidas para efetivar a fenomenologia como método de investigação dos fenômenos psíquicos.

\section{Referências}

Castro, T. G., \& Gomes W. B. (2011). Movimento fenomenológico: controvérsias e perspectivas na pesquisa psicológica. Psicologia: Teoria e Pesquisa, 27(2), 233-240.

Giorgi, A. (2006). Difficulties encountered in the application of the phenomenological method in the social sciences. Análise Psicológica, 3(24), 353-361.

Goto, T. A. (2008). Introdução à psicologia fenomenológica. A nova psicologia de Edmundo Husserl. São Paulo: Paulus.

Heidegger, M. (1989). Ser e tempo, parte I (M. S. Cavalcante, Trad. $8^{\mathrm{a}}$. ed.) Petrópolis: Vozes. (Trabalho original publicado em 1927)

Heidegger, M. (2001). Seminários de Zollikon (G. Arnhold, \& M. F. Almeida Prado, Trads.). São Paulo: EDUC; Petrópolis: Vozes (Trabalho original publicado em 1987)

Heidegger, M. (1991). Meu caminho para a fenomenologia (E. Stein, Trad.). In Os pensadores. São Paulo: Nova Cultural. (Trabalho original publicado em 1963)

Heidegger, M. (1989). Ser e tempo. Petrópolis: Vozes. (Trabalho original publicado em 1927)

Husserl, E. (2007). Investigações lógicas (P. Alves, \& C. Marujão, Trad.), (Vols. 1-2). Lisboa: Centro de Filosofia da Universidade de Lisboa. (Trabalho original publicado em 1901)

Merleau-Ponty, M. (1994). Fenomenologia da percepção (C. A. de Moura, Trad.). São Paulo: Martins Fontes. (Trabalho original publicado em 1945)

Merleau-Ponty, M. (1990). O primado da percepção e suas consequências filosóficas (C. M. Cesar, Trad.). Campinas: Papirus.

Merleau-Ponty, M. (2012). A dúvida de Cézanne (M. E. Pereira, \& P. Neves, Trads.). In O olho e o espirito. São Paulo: Cosacnaify. (Trabalho original publicado em 1945)

Sartre, J-P. (2005). Situações I: críticas literárias (C. Prado, (Trad.). São Paulo: Cosac Naify. (Trabalho original publicado em 1947)

Sartre, J-P. (1948). Esquisse d' une théorie des Emotions. Paris: Hermann et Cie.

\author{
Recebido em 04.07.2013 \\ Primeira decisão editorial em 13.03.2014 \\ Versão final em 01.04.2014 \\ Aceito em 30.04.2014
}

